\title{
Analysis of Modification of Spur Gear Profile
}

\author{
Rafał GOŁĘBSKI, Željko IVANDIĆ
}

\begin{abstract}
The article presents an analysis of the modification of the toothing of spur gears. The aim of the modification of the profile on the tooth tip is to compensate for the tooth deflection under loading and to improve the conditions of gear operation. Cases of longitudinal toothing modification of a convex-convex (Cv-Cv type) tooth are described, where the tooth is biconvex and the gear teeth are convex-concave (Cv-Cc type). The conditions of mating of modified gears have been analyzed. A method of machining gears by the step-by-step method has been proposed, which can be used in unit machining of large-module gears with an arbitrary profile modification system.
\end{abstract}

Keywords: profile modification; spur gear; tooth profile.

\section{INTRODUCTION}

Nowadays spur gears are probably still the most commonly used gears. They are machined primarily by the hobbing method with modular hobs, which is the most efficient method, but also with pull broaches, Fellows cutters, or in the process of finishing machining by gear shaving or grinding by the Maag, Niles or Reishauer methods $[1,2,3]$. Quite often, in unit production, they may be formed using disc- or finger-type modular cutters. This is, however, a little efficient method, and the tools used are generally expensive. Gear machining is most commonly accomplished on special machine tools.Very often, during the manufacture and assembly process, the gears are prone to a number of errors resulting predominantly from the geometric imperfections of their construction and, in addition, the bearings on which the shafts are mounted undergo wear in operation, as a consequence of which they do not meet accuracy standards [4]. This created the need for a concept of the design of such a tooth profile that would ensure the efficient operation of the gear under its poor mating conditions. The forerunner of intensive research on the optimization of the gear design with special emphasis on the tooth profile was M.L. Novikow, who was the first to propose an innovative type of gear with a concave-convex profile [5].

A gear is intended to transmit the rotational motion and the load appropriate to its operation. Therefore, the profile modification needs to be determined from the strength conditions of the gear $[6,7]$. As a result of adherence, the mating tooth trace, after being modified under loading, transforms itself into a punctual contact, which should lie exclusively within the tooth useful surface area [8]. Spur gears with a modified convexconcave profile are characterized by insensitivity to assembly errors and the ability to transmit large loads, moreover increasing the average number of teeth in contact leads to excluding or reduction of the vibration amplitude. The most desirable contact ratio should be about 2, otherwise, it is better to have a contact ratio about 1.7 or higher than 2.3 [9]. Gear wheels with a longitudinal tooth modification are very often used in drive transmission systems in wind power plants.

The technology of gear wheel machining with longitudinal profile modification presents a great challenge in terms of machining kinematics. Practically, the only high-technology machining method is by using a simple finger-type cutter tool with a spherical ending and machining on a CNC machine tool by the step-by-step method. A technology of this type can be competitive to other conventional spur machining methods, especially in the case of large-module gear wheels in gears operating in a responsible regime, or in unit production [10]. Because of the versatility of the method, the step-by-step (sbs) machining technology, being widely used in mould machining areas, can be successfully adapted to the manufacture of gear wheels with a longitudinal profile modification [11].

Step-by-step machining can be accomplished on basic 4-axis CNC milling machines (the fourth rotary axis is that of the workpiece) using simple and inexpensive tools (such as ball-end finger mill), which is consistent with a general worldwide trend to move the machining of gear wheels and gears from specialized machine tools using special tooling to universal $\mathrm{CNC}$ machine tools using universal and simple machining tools $[11,12,13]$.

\section{PROFILE MODIFICATION MAGNITUDE}

In the conducted research it was assumed that the longitudinal tooth modification would vary along the profile height from the value equal to zero at the profile origin point on the base cylinder to the assumed value on the outer diameter - Fig. 1. This is dictated by the fact that the surface of transition of the tooth flank to the cut bottom is not modifiable (in the direction along the tooth), otherwise the transition of the tooth flank into the cut bottom would not be smooth. As a result, the radius of the longitudinal profile modification circle will be variable for successive points at the profile height.
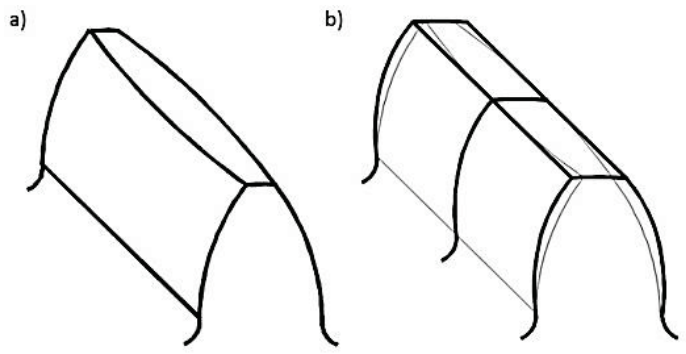

Figure 1 Longitudinal tooth modification concept: a) a tooth with a CV-Cv longitudinal modification; b) an St-St tooth with no longitudinal modification (the thin line denotes the planned modification of the tooth surface) 
During machining, the cutter position, at which the normal to the tooth profile at the gear tooth profile and tool contact point lies in a plane, allows the modification of the tooth by a specific value in the direction normal to the gear wheel tooth surface. It should be noted, however, that a tooth with no profile modification is considered at this stage of discussion.

With a theoretically infinite number of tool positions at the tooth profile height, the partial surface contacts the tool flank along the contact line. The tooth flank is lined with those lines. In each pass, the tool performs motion along a straight line in the horizontal plane. It has been assumed now that, in each pass, the tool moves along a circular arc and the contact line transforms itself into a circular arc. The modification varies from zero (the arc radius being equal to infinity) at the base diameter height to the preset value (and the resulting arc radius value) at the gear wheel outer diameter height.

The longitudinal modification will consist in substituting the tooth generating line at the considered profile point with a circular arc, whose radius will be dependent on the assumed modification at the tooth tips (tooth end face) - Fig. 2, and will be equal (at the tooth tip) to

$$
\rho_{\min }=\frac{\frac{b^{2}}{4}+f_{\max }^{2}}{2 f_{\max }}
$$

where: $f_{\max }$ - magnitude of longitudinal tooth modification at the tip; $\rho_{\min }$ - minimum radius of longitudinal tooth line modification.

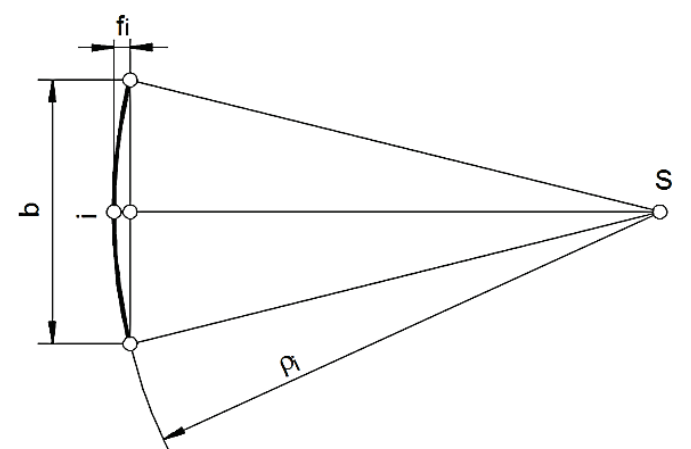

Figure 2 Determination of the radius of the longitudinal gear wheel tooth modification circle

It can be assumed that the modification $f_{\max }$ at the tooth tip should not be smaller than the permissible tooth line deviation on the rim width, being equal to the permissible axis non-parallelism error, with such errors for gears of Class 6 being:

$$
\Delta \delta=\Delta \beta=\sqrt{b}+5
$$

where: $\Delta \delta$ - permissible axis non-parallelism error.

For making gear wheel tooth longitudinal modification, circular approximation function will be used in the machine tool's control system, where the radius is either given or computed by the control system. However, there will be no modification at the gear tooth profile origin point, which means that at this point the modification radius will be equal to infinity. As it is not possible to input such a value to the program, linear interpolation function $\mathrm{G} 0$ will be used at this profile point. By contrast, at the next profile point there will be a minimal longitudinal modification resulting from the maximum circular interpolation radius value acceptable by the machine tool control system.

$$
f_{\text {min }}=\rho_{\text {max }}-\sqrt{\rho_{\max }^{2}-\frac{b^{2}}{4}}
$$

where: $f_{\min }$ - minimal magnitude of longitudinal tooth modification; $\rho_{\max }$ - maximum radius of longitudinal tooth line modification.

Thus, at successive profile points, it will be

$$
\rho_{i}=\rho_{\max }-\frac{\rho_{\max }-\rho_{\min }}{n-1}(i-1)
$$

where: $\rho_{i}$ - radius of longitudinal tooth modification at the profile height.

Obviously, longitudinal modification can be constant at the entire profile height; however, in the light of the above discussion, this does not seem to be a good solution.

\section{ANALYSIS OF GEOMETRY \\ 3.1 Biconvex Tooth Type}

A case of the longitudinal modification of the $\mathrm{Cv}-\mathrm{Cv}$ type tooth, or a biconvex tooth, will be subjected to analysis. The modification of either side of the tooth will be symmetrical; however, this condition does not have to be satisfied. It is specifically the case when we take a maximum longitudinal modification value that is different for either side of the tooth.

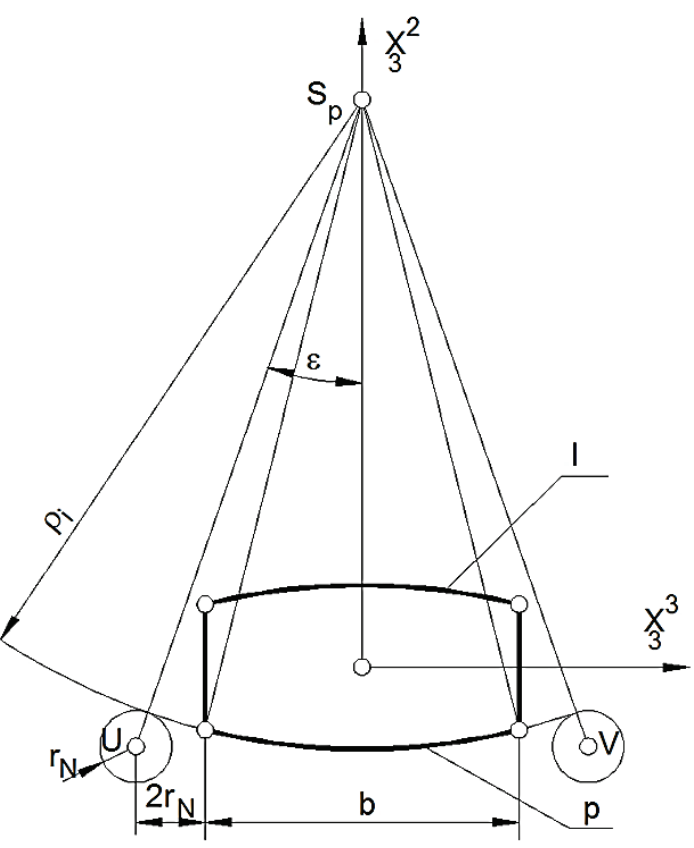

Figure 3 Schematic diagram of the determination of the circular interpolation parameters for longitudinal tooth modification 
To program the successive passes of the tool it is essential to determine the safe initial and end positions (outside the blank material) of the tool centre in the interpolation plane - Fig. 3 .

Assuming that the tool goes beyond the face of the gear wheel by the value of its radius, the half-angle of the arc described by the tool when shaping the tooth flank at a given profile point is as follows (to simplify the notation, the index and the identifying point of the tooth profile have been omitted):

$\sin \varepsilon=\frac{\frac{b}{2}+d_{\mathrm{N}}}{\rho}$

where: $\varepsilon$ - half-angle of tool displacement when shaping the tooth flank at a given profile point; $b$ - gear wheel rim width; $d_{\mathrm{N}}$ - tool diameter; $\rho$ - radius of tooth surface modification at a given point.

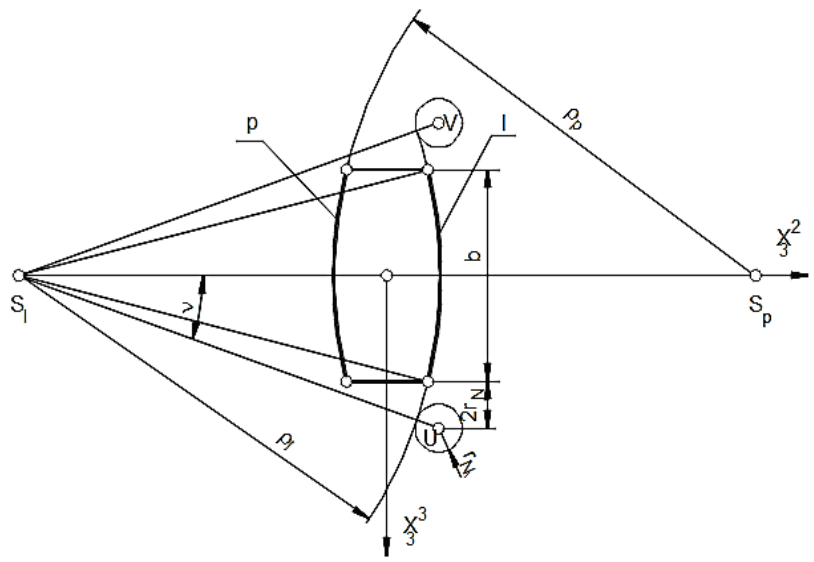

Figure 4 Tool positioning for the Convex-Convex tooth type

So, the coordinates describing the initial tool positions for machining the left- and right-hand tooth sides (denoted with $\mathrm{L}$ and $\mathrm{R}$, respectively) are as follows:

$$
\begin{aligned}
& x^{3(U)}=-\left(\rho+r_{\mathrm{N}}\right) \sin \varepsilon \\
& x^{2\left(U_{\mathrm{R}}\right)}=\rho+x^{2\left(i_{\mathrm{R}}\right)}-\left(\rho+r_{\mathrm{N}}\right) \cos \varepsilon \\
& 3 \\
& x^{2\left(U_{\mathrm{L}}\right)}=-\rho+x^{2\left(i_{\mathrm{L}}\right)}+\left(\rho+r_{\mathrm{N}}\right) \cos \varepsilon
\end{aligned}
$$

The coordinates of the arc centre are equal to

$$
\begin{aligned}
& x^{3(S)}=0 \\
& 3^{2\left(S_{\mathrm{R}}\right)}=\rho+x^{2\left(i_{\mathrm{R}}\right)} \\
& 3^{2\left(S_{\mathrm{L}}\right)}=-\rho+x^{2\left(i_{\mathrm{L}}\right)} \\
& x^{2}
\end{aligned}
$$

and, respectively

$$
x^{3(V)}=-x^{3(U)}
$$

$$
\begin{aligned}
& x^{2(V)}=-x^{2(U)} \\
& I=0 \\
& J=x_{3}^{2(S)}
\end{aligned}
$$

In the case above, the circular interpolation centres are set at the opposite sides of the gear wheel symmetry plane (with the equal modification of both tooth sides) Fig. 4, which facilitates programming.

\subsection{Convex-Concave Tooth Type}

In this case, the analysis is similar to that above, except that the initial positioning of the tool changes. Now, however, one tooth side is convex and the other concave, that is the gear wheel teeth are of the convexconcave type. So, the convex side of one gear wheel's tooth will mate with the concave side of the other tooth in the gear. Therefore, the radius of the convex tooth line must be smaller than the radius of the concave tooth line in order to guarantee the tooth contact to be located at the mid-width of the gear wheel rim - Fig. 5.

To simplify the analysis, it is assumed (of course, a different assumption might be made) that the magnitude of longitudinal modification at the tip of the concave side tooth is the same as the longitudinal modification of the $\mathrm{Cv}-\mathrm{Cv}$ tooth, and the modification of the convex tooth side is two times greater. So, the minimum radius for the concave side will be the same as previously mentioned in Eq. (1).

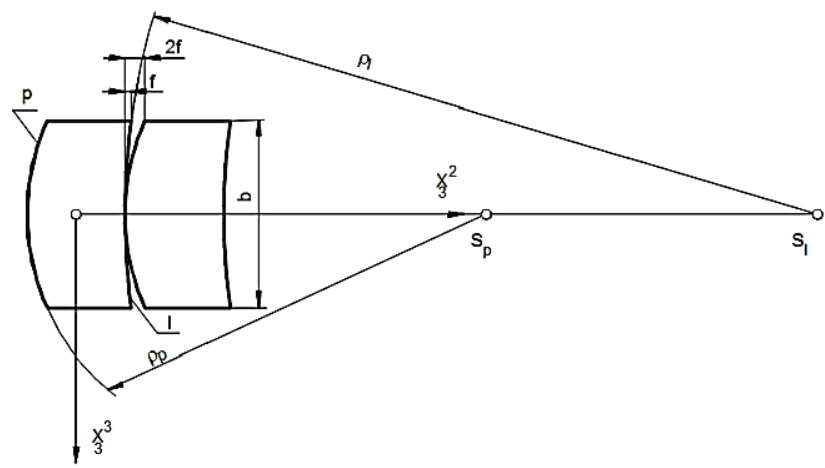

Figure 5 Tool positioning for the Convex-Concave tooth type

For machining the convex and concave sides of a tooth, the centres of circular interpolation are on the same tooth side. Generally, as previous analyses show, the purpose of tooth modification is to enhance the gear's insensitivity to the errors of gear wheel assembly (and also execution). It means that there is a need to depart from mating spur gear wheels. Alternatively, a spur gear wheel should mate with a $\mathrm{Cv}-\mathrm{Cv}$ tooth gear wheel. Gear wheels with $\mathrm{Cv}-\mathrm{Cv}$ teeth can also mate with one another. $\mathrm{Cv}-\mathrm{Cv}$ gear wheels with a modification which ensures that the convex tooth side mates with the concave side may also mate with each another.

\section{TOOTH SURFACE SHAPING}

In the case of spur gears, longitudinal tooth modification is generally difficult to carry out and may be 
associated with not only toothing cutting tool geometry, but also with machining kinematics [14]. However, the development of machining tools and multi-axis CNC machine tools enables the development of toothed gear manufacture technologies. An example can be the possibility of cutting involute spur gears with tooth modification using finger-type mills, that is geometrically simple tools, on universal numerically-controlled CNC machine tools. As has been mentioned earlier, this is consistent with a general tendency to move gear wheel machining from specialized machine tools to universal multi-axis CNC machine tools using versatile, geometrically simple machining tools.

Gear wheels can also be machined with a ball-end finger mill on a 3-axis CNC machine tool furnished with an additional index head for angular positioning of a gear wheel to be machined.
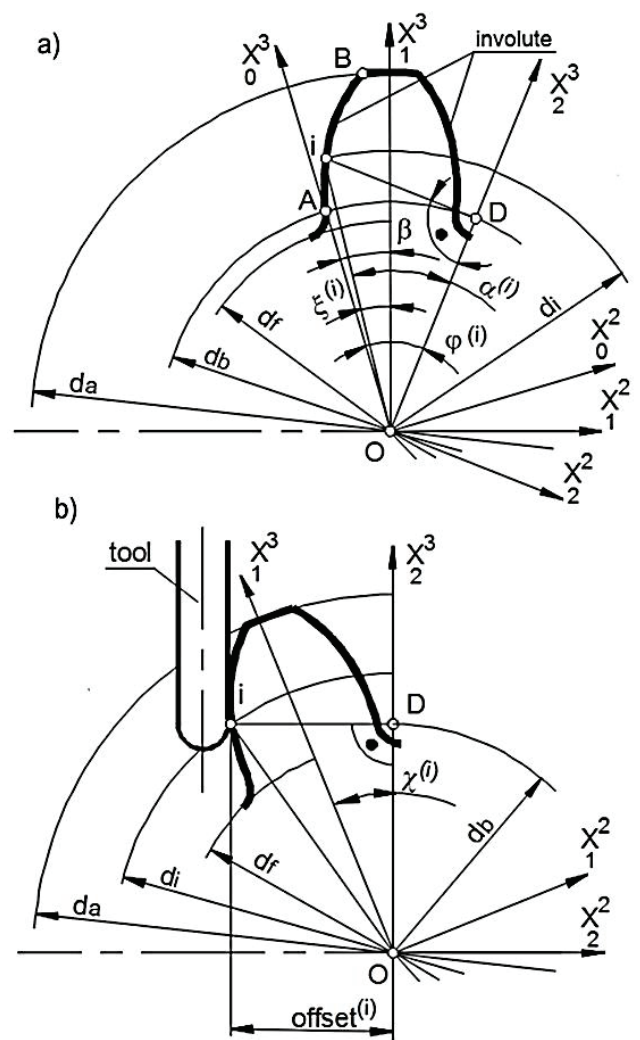

Figure 6 Schematic diagram of tool positioning for Cv-Cc tooth machining

The involute profile of a gear wheel is characterized by the normals to the profile being tangential to its base circle [15]. In that case the gear wheel can be rotated (around its axis) for successive profile points i) so that the normals will assume a horizontal position. So, the points of tangency of the normals to the profile with the base circle (point D) will lie at the point of intersection of the base circle with the vertical ordinate (perpendicular to the circle axis) - Fig.e 6a.

The ball-end finger mill tangential to the machined profile will be, for successive profile points, positioned at a fixed distance from the gear wheel horizontal axial plane, and only its offset towards the horizontal axis (its distance from the gear wheel vertical axial plane) will change [16]. For successive tool passes, the angular position of the gear wheel will also change - Figure $6 \mathrm{~b}$.
On a vertical milling machine it is necessary, for each tool pass, to position the mill at a distance equal to the base circle radius $\left(d_{\mathrm{b}} / 2\right)$ from the gear wheel horizontal axial plane and at a distance equal to the offset (offser $\left.{ }^{(i)}\right)$ from the gear wheel vertical axial plane, and the gear wheel should be rotated by the angle $\left(\chi^{(i)}\right)-$ Fig. 6 .

The gear wheel rotation angle corresponding to the position of the normal to the tooth profile positioned horizontally is equal to

$\chi^{(i)}=\alpha^{(i)}-\xi^{(i)}$

where: $\alpha^{(i)}-$ tooth profile angle at the $i^{\text {th }}$ point (in the $i^{\text {th }}$ tool pass); $\xi^{(i)}$ - angle between the profile point radius and the axis of symmetry $X_{1}^{3}$ of the tooth; $(i)$ - the superscript identifies the tooth profile point (and the successive pass in the toothing cutting process).

Using the angle for positioning the gear wheel on the machine tool is impractical, because the beginning of the involute cannot be identified on the wheel, but it is possible to set the wheel in such a manner that the tooth be positioned symmetrically relative to the vertical axis. On the other hand, the position of the tool as defined by the offset, that is its distance from the wheel vertical axial plane, is determined from the relationship in Fig. 6b, and, from the point of view of building the machining program, will be more practical.

offset $^{(i)}=\frac{d_{i}}{2} \sin \alpha^{(i)}$

where: offset $t^{(i)}$ - mill offset; $i$ - superscript identifying the point on the tooth profile and the pass (position) of the tool in the process of tooth machining (shaping) at that point.

\section{ANALYSIS OF GEAR MATING TRACE}

During mounting of toothed gears, many errors might occur, which will affect the gear operation and durability. One of the most frequently occurring errors is the mounting error that is a twisting of the axes of the mating gear wheels. Using FEM software, thanks to the analysis of the contact phenomenon, we are able to determine, in a very quick and precise manner, the area of mating of two gear wheels $[17,18,19]$. A non-modified straightstraight tooth gear and a modified convex-convex gear were subjected to examination. The computed gear geometry was imported to Ansys Workbench 15.0, a MES program, and subjected to analysis. To investigate the insusceptibility of the corrected gear to change in the location of the tooth mating trace, cases of the mating gear axe parallelism error with varying angle values of, respectively $0.2^{\circ}, 0.5^{\circ}$ and $1^{\circ}$, were modelled, along with modelling the correct axis geometry. Obviously, the indicated deviations represent the total error of both axes of the mating gear wheels. The models apply to a classic gear and gear wheels with a longitudinal correction. Table 1 shows the effect of the axis twisting error for the case of regular gear wheels and longitudinally corrected wheels. 
In the case of involute profile gear wheels with no correction, the effect of the axis twist on the location of the meshing trace is significant. The meshing trace shifts to the tooth edge as the angle increases. At $1^{\circ}$, it is situated only at the mid-tooth, which means that considerable forces occur at its edge, which might cause the edge to crumble, leading to the destruction of the whole gear. When observing the meshing trace for a gear that has longitudinally corrected gear wheels, a considerable difference can be noticed, compared to a non-corrected gear. The meshing trace for the correct mounting is located in the middle of the tooth, which considerably reduces problems associated with the edge contact. In this situation, twisting the axis by up to $1^{\circ}$ causes the trace to only negligibly shift to the lateral tooth direction. Spur gears with enlarged contact area have many advantages as above all, reduction acting loads on the teeth, reduced vibration, noise [20, 21]. However, in the case of shaft misalignments, the resulting errors will definitely cause tooth edge contact, which in consequence can lead to accelerated wear of the whole gear box.

\section{CONCLUSIONS}

In the case of machining, the tooth profile is not a smooth curve, which is due to a finite number of finger mill passes during toothing cutting by the step-by-step method. On the other hand, in the case of other technologies, as, for instance, cutting cylindrical gears by the hobbing method using a hob, the gear wheel profile is also multiangular, which is due to a finite number of blades on the tool perimeter. The tooth surface can be determined as the envelope of a family of tool action surfaces. By contrast, the hob action surface is the locus of blade cutting edges and is described as a continuous surface (it is a surface with a theoretically infinite blade action number). In such a case, the gear tooth flank, determined as the envelope, will be a smooth surface.

A similar situation will be for machining cylindrical gear wheels by the Fellows chiselling method, where the tool is the gear wheel shape and the machining takes place by turning of two gear wheels. The angularity of the machined gear wheel results from the finite number of tool positions in the process of turning (the tool performs reciprocating chiselling motion by turning each time by a small angle) of the tool and the wheel.

In the case of machining the gear wheel tooth surface with a small-diameter finger mill, with each pass of the tool, a partial surface with a circular profile (corresponding to the profile of the spherical ending of the ball-end finger mill) is generated, which contacts the machined gear wheel profile at one point. In subsequent passes, successive partial surfaces (described by the finger mill in the gear wheel system) are generated, which contact linearly the machined surface. As a result, after many tool passes, an angular-profile gear wheel surface will be machined with the accuracy relative to the involute profile depending on the number of tool passes. With an infinite number of passes, this will be a smooth surface which will be the envelope of partial surfaces generated upon each tool pass. Considering the fact that the partial surface is formed with a ball-end finger mill with the hobbing method and the gear wheel tooth surface is the envelope of those partial surfaces, this is a case of two-parameter hobbing in gear toothing machining with a finger mill. The action surface of a tool, which is the ballend finger mill, and the machined surface are not coupled (not mutually enveloping), therefore the step-by-step (sbs) machining technology will enable toothing with an arbitrary (rectilinear, parabolic, or elliptic) profile to be cut, which is undoubtedly an advantage.

Table 1 Effect of the mating gear wheel axis twisting error on the mating trace position

\begin{tabular}{|c|c|c|}
\hline \multirow{2}{*}{$\begin{array}{c}\text { Gearbox axis } \\
\text { angle error }\end{array}$} & \multicolumn{2}{|c|}{ Tooth type } \\
\cline { 2 - 3 } & Straight - straight & Convex - convex \\
\hline $0^{\circ}$ & & \\
\hline & & \\
\hline & & \\
\hline & & \\
\hline
\end{tabular}

Gear wheels, in which a longitudinal correction has been introduced, are characterized by better operation parameters; a problem might only be posed by their manufacture. In unit production, a CNC machine tool can successfully be used; in the case of mass production, however, this is not viable in terms of both economy and time. Employing a gear with a longitudinal tooth modification is fully justifiable for gears to be used for specialized purposes, while gear wheels, whose machining technology has been the base of tools and machines for a long time, still have a wider application. Another important aspect of this study is the confirmation of the positive effect of longitudinal correction on the operation of the gears in question. Notwithstanding their numerous advantages, the problem of their manufacture is often the reason they do not find a wider application. They give way to the conventional involute profile which, at least until corrected gear wheels are manufactured in an efficient, cheap and fast manner, will probably continue to be most commonly used. 


\section{REFERENCES}

[1] Ochęduszko, K. (1972). Toothed gears, execution and assembly. Volume II, Warsaw: WNT.

[2] Skoć, A. \& Świtoński E. (2016). Toothed gears. The principles of operation. Geometric and strength calculations. Warsaw: WNT.

[3] Litvin, F. L. (1998). Development of Gear Technology and Theory of Gearing. Chicago: NASA Reference Publication 1406.

[4] Pisula, J. \& Płocica, M. (2014). The effect of bevel gear assembly errors on the quality of meshing. Gliwice: Scientific Workbooks of the Silesian University of Technology. Series Transport, 82.

[5] Bob, M. \& Bob, D. (2011). Aspects regarding profile modification of spur gears. Annals of MteM for 2011 \& Proceedings of the 10th International MteM Conference. 29-34.

[6] Marković, K. \& Franulović, M. (2011). Contact stresses in gear teeth due to tip relief profile modification. Engineering Review, 3, 119-126.

[7] Marković, K. \& Vrcan, Ž. (2016). Influence of Tip Relief Profile Modification on Involute Spur Gear Stress. Transactions of FAMENA, 40, 59-70. https://doi.org/10.21278/TOF.40205

[8] Radzevich, S. P. (2012). Theory of Gearing Kinematics, Geometry, and Synthesis. Boca Raton: CRC Press. https://doi.org/10.1201/b12727

[9] Rackov, M., Milovančević M.,Vereš, M., Banić M., Miltenović, A. (2014). Optimization of HCR gearing geometry using generalized particle swarm optimization algorithm. Technical gazette, 21(4), 723-732.

[10] Gołębski, R. (2017). Parametric programming of CNC machine tools. MATEC Web of Conferences 94:07004. https://doi.org/10.1051/matecconf/20179407004

[11] Radzevich, S. P. (2010). Gear Cutting Tools, Fundamentals of Design and Computation. Boca Raton: CRC Press. https://doi.org/10.1051/matecconf/20179407004

[12] Litvin, F. L. \& Fuentes, A. (2014).Gear Geometry and Applied Theory. Cambridge: Cambridge University Press.

[13] Stryczek, R. \& Pytlak, B. (2011). Flexible programming of machine tools. Warsaw:PWN.

[14] Nieszporek, T. (2013). Cutting tool design and external cylindrical toothing technology. Czestochowa: Press of the Czestochowa University of Technology.

[15] Boral, P. (2018). Technological determinants of the teething geometry of worm gears with either a fixed or variable pitch worm. Czestochowa: University Press of the Czestochowa University of Technology.

[16] Boral, P. (2017). Determination of the Wormwheel Tooth Surface, Procedia Engineering, 177, 57-63. https://doi.org/10.1016/j.proeng.2017.02.183

[17] Gołębski, R. (2012). Finite Element Method Model for Analysis of Contact Stress of Spur Gear. Mechanik, 7, 237242.

[18] Litvin, F. L., Chen, J. S., Lu J., \& Handschuh, R. F. (1996). Application of finite element analysis for determination of load share, real contact ratio, precision of motion and stress analysis. Journal of Mechanical Design, Transaction of the American Society of Mechanical Engineers, 118, 561-567. https://doi.org/10.1115/1.2826929

[19] Lagutin, S., Verhovski, A., \& Dolotov, S. (1996). Technological design of wormgears with localized contact. The $2^{\text {nd }}$ Int. Conf. Power Transmissions'06 / Novi Sad. 177-182.

[20] Yu, S. \& JengTsai, Y. S. (2016). A computerized method for loaded tooth contact analysis of high-contact-ratio spur gears with or without flank modification considering tip corner contact and shaft misalignment. Mechanism and Machine Theory, 97,190-214. https://doi.org/10.1016/j.mechmachtheory.2015.11.008

[21] Pop, N. \& Creţu, S. (2017). Tooth contact analysis of spur gears. Part 2-Analysis of modified gears. Retrieved from https://www.matec-conferences.org/articles/matecconf/abs/ 2017/26/matecconf_imane2017_07016/matecconf_imane20 17 07016.html

Contact information:

Rafał GOŁĘBSKI, Dr Eng

Czestochowa University of Technology

Institute of Mechanical Technologies

Al. Armii Krajowej 21,

42-201 Czestochowa, Poland

E-mail: rafal@itm.pcz.pl

Željko IVANDIĆ, Prof. Dr. Sc. Mech. Eng

University of Osijek

Mechanical Engineering Faculty of Slavonski Brod

Trg I. B. Mazuranic 2

35000 Slavonski Brod, Croatia

E-mail: zivandic@sfsb.hr 